\title{
Importancia del cuy en la región altoandina de la provincia de Huaral
}

Recibido: 17/05/19

Aprobado: 04/08/19
Pieter van Dalen Luna

Universidad Nacional Mayor de San Marcos pvandalen2@hotmail.com

\section{RESUMEN}

El presente artículo presenta un panorama histórico sobre la importancia del cuy en las comunidades campesinas de la cuenca alta del río Chancay-Huaral. Esta importancia se mantiene vigente desde el periodo prehispánico del Intermedio Tardío (cultura Atavillos), tal como se aprecia en las evidencias arqueológicas recuperadas en sitios como Rupac, Marca Piche, Purunmarca y Araro; sitios investigados con excavaciones en los últimos cinco años. Las fuentes etnohistóricas refieren también la importancia de este animal en las comunidades de indígenas de los diferentes curatos. En la actualidad, la importancia del cuy se mantiene vigente en las comunidades altoandinas de la provincia de Huaral, con fines medicinales y alimenticios.

KEYwORDs: arqueología; etnografía; comunidades campesinas; Huaral; cuy.

\section{Importance of cuy in the high Andean region of the province of Huaral}

\begin{abstract}
This article presents a historical overview of the importance of guinea pigs in the peasant communities of the upper Chancay - Huaral river basin. This importance remains valid from the prehispanic period of the Late Intermediate (Atavillos culture), as it is appreciated in the archaeological evidences recovered in places like Rupac, Marca Piche, Purunmarca and Araro; Sites investigated with excavations in the last five years. Ethnohistoric sources also refer to the importance of this animal in the indigenous communities of the different parishes. At present, the importance of the guinea pig remains in force in the high Andean communities of the province of Huaral, with medicinal and nutritional purposes.
\end{abstract}

KeYwORDs: archeology; ethnography; peasant communities; Huaral; cuy. 


\section{Introducción}

E 1 cuy es un animal típico, famoso y muy reconocido en la América Andina, en especial en Perú, Bolivia y Ecuador. Es un pequeño animalito doméstico, muy utilizado en fines diversos: como alimento de alto valor proteico, como instrumento de curación y adivinación, entre otros; aunque en países de América del Norte y Europa es utilizado como mascota. El nombre autóctono es cuy, aunque a través de la historia, ha sido denominado con otros nombres extranjeros como conejillo de indias (español), cobaya (francés), o cerdo de guinea (ingles) debido a que se le atribuía que era originario de las costas africanas de Guinea (Altamirano; 1986: 5, Wing; 1975, Gade; 1967, Henan; 1956). En los Andes existe hoy una población estable aproximada de 35 millones de cuyes, con una mayor densidad en el Perú, donde anualmente se obtiene una producción de 16500 toneladas de carne derivadas de más de 65 millones de cuyes, con una población estable de aproximadamente 22 millones de animales criados en sistemas de producción familiar, del cual el 44.6\% es para autoconsumo (Chauca; 1997: 9).

El cuy es un mamífero pequeño del orden de los roedores. Su nombre científico es cavia porcellus. Según los investigadores, existen en América por lo menos tres variedades hermanas de cuyes: la Cavia aperea, con mayor distribución entre el sur de Brasil, Uruguay, el noeste argentino y sureste de América del Sur; Cavia tschudi en las zonas altoandinas de Perú, Bolivia y el noroeste argentino; y Cavia porcellus en todas las regiones antes mencionadas además de Ecuador, Guayana, Venezuela y Colombia (Wing; 1975, Altamirano; 1986, Cabrera; 1953, Pulgar; 1952). Estudios moleculares y genéticos han demostrado que el cuy domesticado procede del ancestro silvestre: Cavia tschudi, y que este proceso se habría dado en los Andes occidentales, mas no en los Andes orientales (Spotorno, Manríquez, Fernández, Marín, Gonzales y Wheeler; 2007).

En las comunidades altoandinas y en los valles interandinos y amazónicos, la crianza del cuy se da a nivel familiar, es decir, cada familia cría cuyes dentro del espacio doméstico cotidiano (Bolton y Calvin; 1981, Bolton, Calvin y Flores; 2012). Los cuyes pueden vivir en los cuyeros ubicados en áreas contiguas a la cocina o al interior de este espacio, junto al fo- gón. Son compañeros inseparables de los campesinos altoandinos y de valles, pues casi siempre viven junto a las cocinas en las casas, estancias o en abrigos calientes (Altamirano; 1986: 7). Presenta una gran capacidad de adaptación a diferentes ecosistemas con múltiples realidades climáticas (Guillén, Grandez, Chauca, Chauca y Valencia; 2015: 69); pudiéndose adaptar desde el nivel del mar hasta alturas por encima de los 4500 metros, con una mayor distribución en la sierra (92\%), seguido por la costa $(6 \%)$ y la selva (2\%), (Chirinos, Muro, Concha, Otiniano, Quezada, Ríos; 2008: 14).

\section{El cuy en periodos prehispánicos}

El cuy es un animal que en periodos prehispánicos adquirió gran importancia entre las sociedades andinas, existiendo evidencia de su uso desde el periodo Lítico. Casi todos los cronistas coloniales tempranos hacen referencia al uso del cuy, al cual algunos llamaron como conejillos de indias, existiendo múltiples informaciones sobre su importancia durante el Tawantinsuyu. El uso del cuy giraba en tres funciones principales: con fines alimenticios, debido a su alto valor proteico; con fines ritual religioso, como condimento importante en las actividades religiosas; y como instrumento de adivinación y medicinal, mediante el sobado.

Los primeros españoles que invadieron el Tawantinsuyu y sus autoridades eclesiásticas, vieron con desprecio y recelo al cuy, debido a la gran importancia que este animalito tenía en casi todos los aspectos de la vida diaria de la civilización andina. Por ello, en 1576 los curas españoles solicitaron al arzobispo de Lima, Loayza, el exterminio de todos los cuyes en el nuevo Virreynato, a lo cual el arzobispo se negó, ya que podría desencadenar en levantamientos por todo el territorio andino (Antúnez de Mayolo; 1980).

El cuy es muy apreciado como producto alimenticio en todas las sociedades andinas prehispánicas, y aún hasta la actualidad se sigue preparando numerosos potajes a base de cuy. No había festividad religiosa, social o familiar, donde no se prepare el cuy en forma asada o sancochada; pues se trataba de un potaje difusamente conocido en los Andes, obtenida en condición silvestre o doméstico (Espinoza; 1997: 
132). Al respecto, José de Acosta señala: «Hallanse en la sierra del Peru, donde tambien hay otro animalejo muy comun que llaman cuy, que los indios tienen por comida muy buena, y en sus sacrificios usaban frecuentisimamente ofrecer estos cuyes. Son como conejuelos, y, tienen sus madrigueras debajo de y en partes hay donde la tiene toda minada. Son algunos de ellos pardos, otros blancos y diferentes» (Acosta; 1590: libro cuarto: XXXIX).

Durante los matrimonios, el cuy jugaba un papel importante en la comida, al igual que como instrumento de adivinación: "Y llebaban cuyes, charqui y coca y un haz de paja y algunos, que eran ricos, ropa comforme su posible y con ello, como esta dicho, iban a casa dela nobia a los padres, o parientes de ella, y selo presentaban y pedian a su hija por muger, y ellos se la daban y, concertado, hacian su acatamiento y derramaban paja por la casa donde se sentaban todos; y dela lena que llebauan encendian fuego y comian y bebian la chicha que abia traido» (Murúa; 1590: Libro II, capítulo XVI).

En todas las viviendas, la población de las diferentes provincias que conformaban el Tawantinsuyu, criaban cuyes al interior de las áreas domésticas: «La gente plebeya en general era pobre de ganado (si no eran los Collas, que tenian mucho), y por tanto padecia necesidad de carne, que no la comian sino de merced de los curacas o de algun conejo que por mucha fiesta mataban, de los caseros que en sus casas criaban, que llaman coy» (Garcilaso; 1609: capítulo VI).

Otra principal función que tuvo el cuy en tiempos andinos prehispánicos fue como condimento religioso, utilizado principalmente para sacrificarlo en las festividades $\mathrm{u}$ ofrendas a personajes relevantes de la sociedad, pero principalmente a las divinidades que formaban parte del panteón religioso andino. Las ofrendas entregadas a las divinidades estaban conformadas por cuyes sacrificados, camélidos sacrificados (llamas o alpacas, principalmente), hojas de coca, maíz, chicha de maíz, objetos de metales (oro, plata y cobre), spondyllus (mullu) y otros ingredientes. El anónimo Jesuita (1594: capítulo sacrificios) señala que: "Tambien sacrificaba unos animalejos que llaman cuy, y diversos pajaros y otras aves para diversas necesidades». Juan de Matienzo (1567: capítulo XLIV), también describe los ingredientes utilizados en las ofrendas religiosas: "Ponen por inconviniente que la ofrecen al demonio: no es sola la coca la que ofrecen, sino todo lo que tienen en mucho: el maiz y chicha que comen y beben, los corderos de la tierra, los cuyes, las mantas y camisetas que visten, y la mesma plata y oro, y todas las demas cosas. Segun esto, debiaseles vedar el comer y beber y vestir, y todo lo demas, cosa bien sin termino ni razón».

Los primeros espańoles que llegaron a los Andes para invadir el Tawantinsuyu, quedaron sorprendidos y horrorizados de cómo había por todo el imperio especialistas dedicados a la adivinación de sucesos y curación de enfermedades mediante la sobada del cuy. Cabello de Valboa (1586: tercera parte, capítulo XXII), señala que los especialistas que adivinaban con maíz se llamaban "Hachu», mientras que aquellos que adivinaban con el cuy se llamaban "Ayllacos", a quienes era muy frecuente hallarlos por todo el imperio: "Otros auia llamados Hachu, que hechavan suertes con Maiz de diferentes colores, y con las inmundicias de sus cuies y ganados, y con otros animalejos, y granos para el tal efecto aplicados, tambien llamauan a los de este oficio Ayllacos y eran muy comunes en toda la tierra». Joseph de Arriaga (1621: capítulo III), señala por su parte, que las personas especializadas en mirar y adivinar con cuyes tenían otro nombre: «Hacaricuc, o Cuyricuc es el que mira cuyes, y abriendoles con la una adivina por ellos, mirando de que parte sale sangre o que parte se menea de las entranas».

En el primer siglo de dominación hispana, la crónica del Anónimo Jesuita (1594: capítulo adivinos), describe como se realizaba la adivinación con el cuy, mediante el sacrificio de este animalito: «Si veia el confesor que el penitente no descubria todo su pecho, o tenia sospechas dello, luego hacia alli un sacrificio de un cuy, que es como conejuelo o como raton muy grande, o de otro animal o sabandija cualquiera, $y$ abierto el animal, y haciendo sus conjuros y hechicerias, decia que adivinaba que aquel le escondia pecados, y dandole con la piedra, le hacia descubrir todo lo que tenia; y en todo lo demas hacia lo que queda dicho".

\section{Importancia del cuy en la cultura Atavillos}

La cultura Atavillos se desarrolló en periodos prehispánicos tardíos en la cuenca alta del río ChancayHuaral, hoy provincia de Huaral. No fue la única 
entidad sociopolítica que se desarrolló en este territorio, pues en la subcuenca del río Huataya se desarrolló la cultura Iguari. Los pueblos Atavillos más grandes e importantes se emplazan en la cima de los cerros más elevados, en áreas de difícil acceso (con fines defensivo) y desde donde se tiene una visión panorámica paisajística general de cada subcuenca. Esto último con el objetivo del aprovechamiento de recursos de diferentes ecosistemas mediante el control vertical de pisos ecológicos (Murra; 1972). Entre los principales pueblos atavillanos tenemos: Rupac (actual Comunidad campesina de San Salvador de Pampas), Chiprac (San Juan de Uchucuanico), Añay (Pallac), Cachirmarca (San Juan de Viscas), Yaros (Lampián), Curcos (Cárac), Purunmarca (San Miguel de Vichaycocha), Marca Piche (San José de Baños), Rancocha (San Pedro de Pirca), Araro (Santa Cruz de Andamarca), Puchune (Pasac), Huampón (Huaroquín), entre muchos otros. Son más de 80 los pueblos grandes de la cultura Atavillos distribuidos en las 30 comunidades campesinas altoandinas de la provincia (en otras seis hay más de 30 pueblos de la cultura Iguari).

La arquitectura característica atavillana son los edificios tipo Kullpi, de hasta más de siete metros de altura, planta cuadrangular, con una cámara principal interna de planta ovalada a la que se accede desde el exterior por medio de un vano pequeño rectangular (algunos tienen ante-cámara). Presenta numerosas cámaras secundarias dispuestas alrededor de la principal y en varios niveles verticales, a las cuales se accede desde la principal por vanos pequeños. La función de estas cámaras secundarias era múltiple, desde áreas de cocina, almacenamiento y estructuras funerarias; mientras que en la cámara principal se desarrollaban principalmente actividades domésticas, aunque en algunos casos se han encontrado ofrendas debajo del piso. Además de los kullpis había también en los pueblos chullpas, de única función funeraria. El patrón de distribución interna de los pueblos está conformado por conjuntos arquitectónicos de kullpis y chullpas distribuidas alrededor de patios empedrados; articulados por áreas de circulación formado por pasadizos y caminos epimurales. Las edificaciones fueron construidas sobre plataformas elaboradas para dar mayor horizontalidad al terreno.

Desde el año 2014 hasta la actualidad, bajo el auspicio y financiamiento de la Universidad
Nacional Mayor de San Marcos a través de los proyectos de investigación, se han desarrollado investigaciones arqueológicas con excavaciones en los sitios de Purunmarca (2014) y Rupac (2015). Por su parte con auspicio y financiamiento de la Municipalidad Distrital de Santa Cruz de Andamarca se realizaron excavaciones en Araro (2017); mientras que en Marca Piche se realizó en base al convenio interinstitucional entre la Universidad Nacional Mayor de San Marcos y la Comunidad Campesina de San José de Baños (2015, 2017). Las excavaciones en estos cuatro pueblos arqueológicos tuvieron el objetivo de determinar las características de las ocupaciones Atavillos e Inca, corroborar si eran estas las únicas ocupaciones, determinar la funcionalidad de los edificios tipo Kullpi y caracterizar los contextos funerarios atavillanos y el culto a los ancestros (van Dalen; 2007, 2014, 2016, van Dalen, Grados, Medina y Malpartida; 2016).

Las excavaciones en estos cuatro sitios han permitido recuperar cuantiosa información sobre la funcionalidad de los kullpis, características de los contextos funerarios y el culto a los ancestros y divinidades. Se han recuperado una considerable muestra de restos óseos de cuyes, correspondientes a individuos completos o huesos aislados.

En el sitio de Purunmarca, como parte de los materiales asociados a los contextos funerarios Atavillos o de ofrendas al apu Quirupalca, se han recuperados restos de cuyes. En la unidad de excavación 4 se halló, por ejemplo, la ofrenda de un cuy colocado en la esquina noreste externa de una edificación, con el cuerpo orientado al cerro (apu tutelar), de noroeste a sureste, dispuesto en un área de distribución ovalada, de $0.32 \mathrm{~m}$ de largo (noroeste-sureste), $0.12 \mathrm{~m}$ de ancho (noreste-suroeste) y $0.05 \mathrm{~m}$ de profundidad. El cráneo del cuy se ubica hacia el lado sureste mientras los elementos óseos que conforman su cuerpo se ubican hacia el lado noroeste; al retirar el cráneo se observa la mandíbula, la cual conserva los dientes. Este contexto no presentó ningún elemento asociado. Así mismo, en la unidad 1 se recuperó en la capa A un diente de cuy, además de la pelvis derecha de un cuy joven, entremezclado con el desmonte producto del colapso del edificio Kullpi.

En el contexto funerario 1 de la unidad 2 se halló los restos de un cuy joven que formaba parte de las ofrendas del contexto funerario de cinco individuos humanos (una mujer joven adulta, un varón joven 

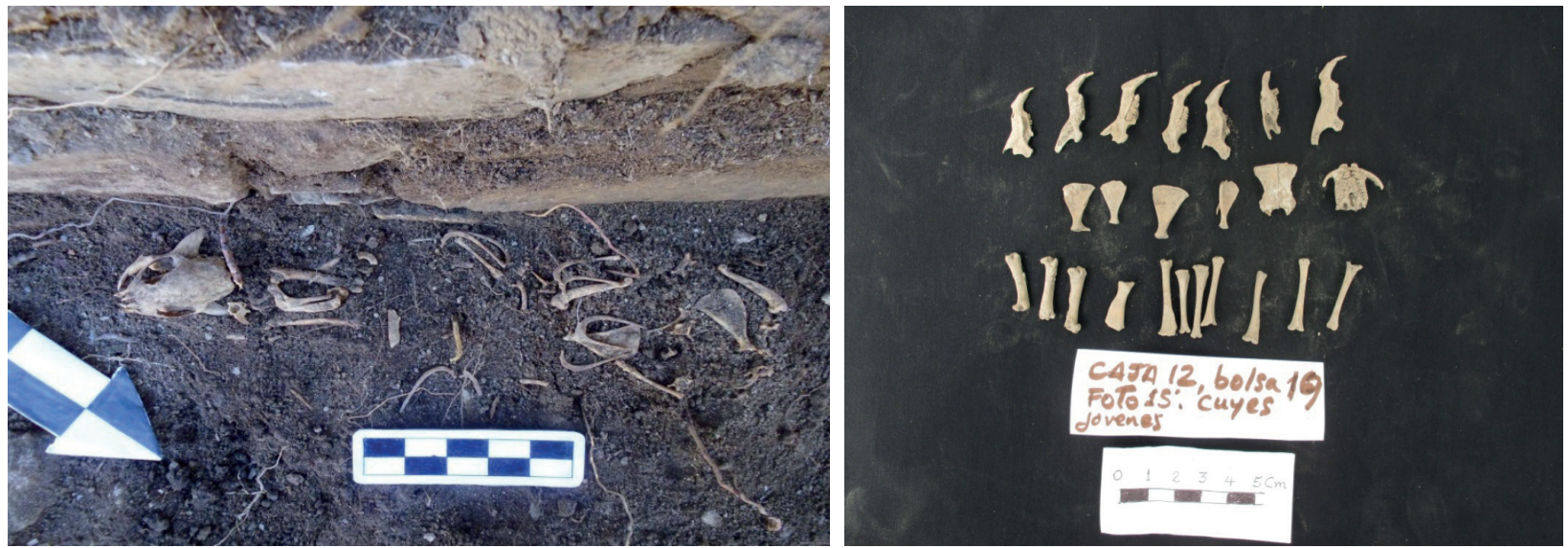

Figura 1 (izquierda): Vista de detalle del Contexto № 01 correspondiente a un cuy, recuperado de la unidad de excavación 4 de Purunmarca. Figura 2 (derecha): Siete mandíbulas de cuyes (Cavia porcellus): 4 derechos y 3 izquierdos. Son jóvenes pequeños y sus esqueletos postcraneales están completos.

adulto, dos bebes y un niño), asociado a la ofrenda de un Ayno (Fulica ardesiaca) y a una flauta elaborada en hueso de camélidos. Un poco más arriba en la misma unidad se había hallado los restos de otro cuy (una mandíbula derecha y un húmero no fusionado derecho) asociados con restos óseos de una alpaca y restos óseos humanos de un bebe (como parte de un contexto funerario disturbado). En otras unidades de excavación como la 14,9 y 11 se recuperaron también restos de cuyes como parte de ofrendas de los contextos funerarios, siempre asociado a los restos de otros animales como llamas, alpacas, tarukas, vizcachas, entre otros; así como a vasijas cerámicas de estilo Atavillos. En la unidad 7 se halló al interior de un Kullpi los restos de cuyes asociados a desechos de comida. Las evidencias halladas en Purunmarca indican que el cuy formaba parte de los banquetes de los muertos y de los dioses, así como era parte de la dieta de la población de este sitio.

El sitio de Rupac se ubica también en la cuenca alta del río Chancay, conformado por cuatro sectores con edificios Kullpi en buen estado de conservación. Se trata del sitio representativo de la cultura Atavillos, por su buen estado de conservación. Las excavaciones realizadas al interior de estas edificaciones permitieron identificar múltiples actividades: en la cámara principal hay evidencias de actividades domésticas, en las cámaras secundarias se halló contextos funerarios y áreas de almacenamiento. Entre los materiales de las áreas domésticas, como entre los materiales que formaban parte del ajuar de los contextos funerarios, se recuperó una considerable muestra de restos óseos animales, entre estos de: camélidos (alpacas, vicuńas y llamas; la mayoría con evidencias de haber sido sometidos al fuego, al parecer preparados como pachamanca o preparados con huatia), taruca (Hippocamelus antisensis), vizcacha (Lagidium peruanum); cérvidos (Hippocamelus antisensis), cuy (Cavia porcellus), aves altoandinas, venado de cola blanca (Odocoileus virginianus), entre otros. Villar Córdova (1982: 316) señalaba que la población atavillana era carnívora, con alto índice de consumo de carne, entre estos de cuy. Además, se han recuperado restos óseos de otros animales utilizados como ofrendas funerarias o ceremoniales, como: zorro o Atoj (Pseudolopex culpaeus), zorrino o ańas (Conepatus rex), aves altoandinas como el yanavico (Plegadis ridgwayi), el ayno o gallareta andina (Fulica ardesiaca), roedor pequeño o Ukush (Phyllotis pictus), cánidos (Canis familiaris), pumas (Felis concolor) y ranas procedentes de las lagunas cercanas (Batrachophrynus macrostomus).

Además, se han recuperado huesos de animales trabajados, principalmente de camélidos, con el objetivo de elaborar artefactos como espátulas, cucharas, choqche o ruqui (instrumento textil) y flautas musicales; así como instrumentos ceremoniales como las illas, algunas de ellas encontradas con restos de cal que eran para ofrendar con coca. Se ha recuperado restos de charqui de camélido (alpaca). Además, se recuperó una piedra pómez de procedencia marina, desgastada en sus bordes, asociada a restos óseos de camélidos, cérvidos y hojas de coca. 

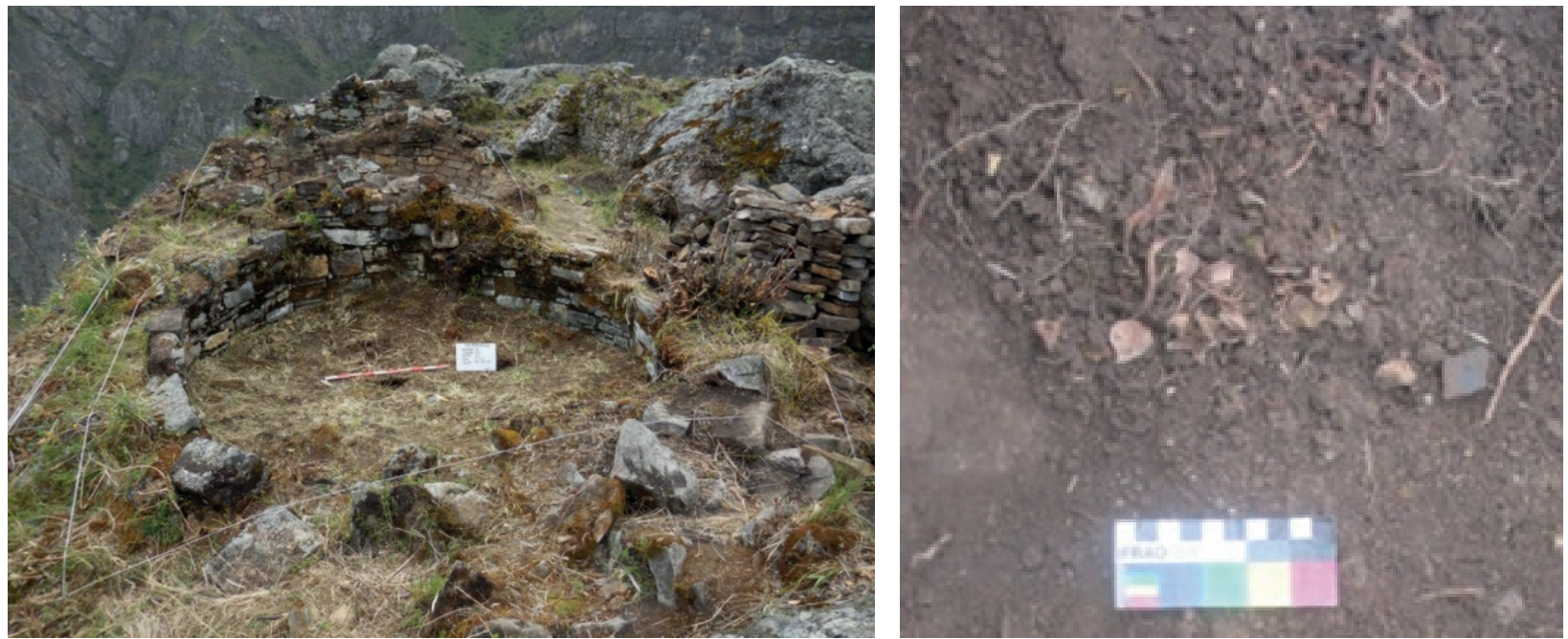

Figura 3 (izquierda): Vista del recinto circular 1 del sector D, en cuyo interior se emplazó la unidad de excavación 3. Sitio arqueológico Marca Piche. Figura 4 (derecha): vista de detalle de la ubicación del entierro 1, unidad 3 (Marca Piche), correspondiente al entierro de un cuy.

En el sector A se ha recuperado restos de cuyes en la unidad 11, emplazada al interior del Kullpi 14. En la capa A, se halló coprolitos de cuy dispersos por toda el área interna de la cámara principal, lo que evidencia que estos animalitos vivieron al interior de estas edificaciones. En la unidad 10, ubicada al interior del kullpi 15, distribuida al interior por dos cámaras o recintos (R1 y R2), se halló en la capa $\mathrm{A}$ del R2 el llamado "desecho 1», el cual se compone de restos óseos de camélidos, cuyes, aves, además de algunos restos botánicos como tusa de maíz y pepa de lúcuma.

Por último, el tercer asentamiento Atavillos que ha sido investigado con intervenciones físicas en el monumento es el de Marca Piche (van Dalen; 2007, 2010, 2014a). El sitio arqueológico de Marca Piche se constituyó en periodos prehispánicos tardíos como uno de los más importantes centros administrativos de la cuenca alta del río Chancay-Huaral, y en el más importante en la sub cuenca del río Baños. Tras la anexión de la región al Tawantinsuyu, los Incas edificaron un conjunto de estructuras circulares en la parte superior, respetando los Kullpis y otras estructuras Atavillos.

Las excavaciones en las dos temporadas de 2015 y 2017 permitieron recuperar abundantes restos de cuyes al interior de las edificaciones, principalmente de los kullpis. Por ejemplo, en la temporada 2015, en la unidad de excavación 3 ubicado hacia el lado norte del sector $\mathrm{D}$, en el primer recinto circular (Tawantinsuyu) ubicado en la parte superior, se halló en la capa A entremezclado con tierra que ha colapsado de los muros del recinto, fragmentos de cerámica y osamenta animal; así como el Entierro 1, (lado noreste de la estructura circular), conformado por restos óseos (cráneos, vertebras y huesos menores) de un cuy, depositados sobre un colchón de tierra de coloración semioscura. Posteriormente, en la capa B se recuperó entremezclado con la tierra de la capa, los restos casi completos de por lo menos tres cuyes jóvenes ( 6 a 8 meses de edad), identificándose los siguientes huesos: un esqueleto completo, diez fragmentos de cráneo, dos mandíbulas, hay doce dientes sueltos, catorce vértebras cervicales, torácicas y lumbares, veinticuatro costillas, dos escápulas, dos húmeros, dos radios, dos cúbitos, dos pelvis, un sacro, dos fémures, dos tibias, dos rótulas, catorce falanges y accesorios.

En la unidad de excavación 9 de Marca Piche, también se recuperaron restos de cuyes. Conforme se fue desarrollando la excavación se fue identificando el área de dos chullpas, las cuales fueron definidas como Subunidad I y Subunidad II. La chulpa 2 de esta unidad tiene una altura conservada de aproximadamente un metro, 1.80 metros de largo y 1.00 metros de ancho, emplazado sobre la roca madre natural. La capa Superficial de esta chulpa, está compuesta por tierra suelta de granos finos, de color gris. Al interior de esta capa se registró la presencia de material cultural compuesto por algunos fragmentos de cerámica, restos de textiles (entre ellos un pedazo de tejido de color rojo oscuro), algunos restos óseos 


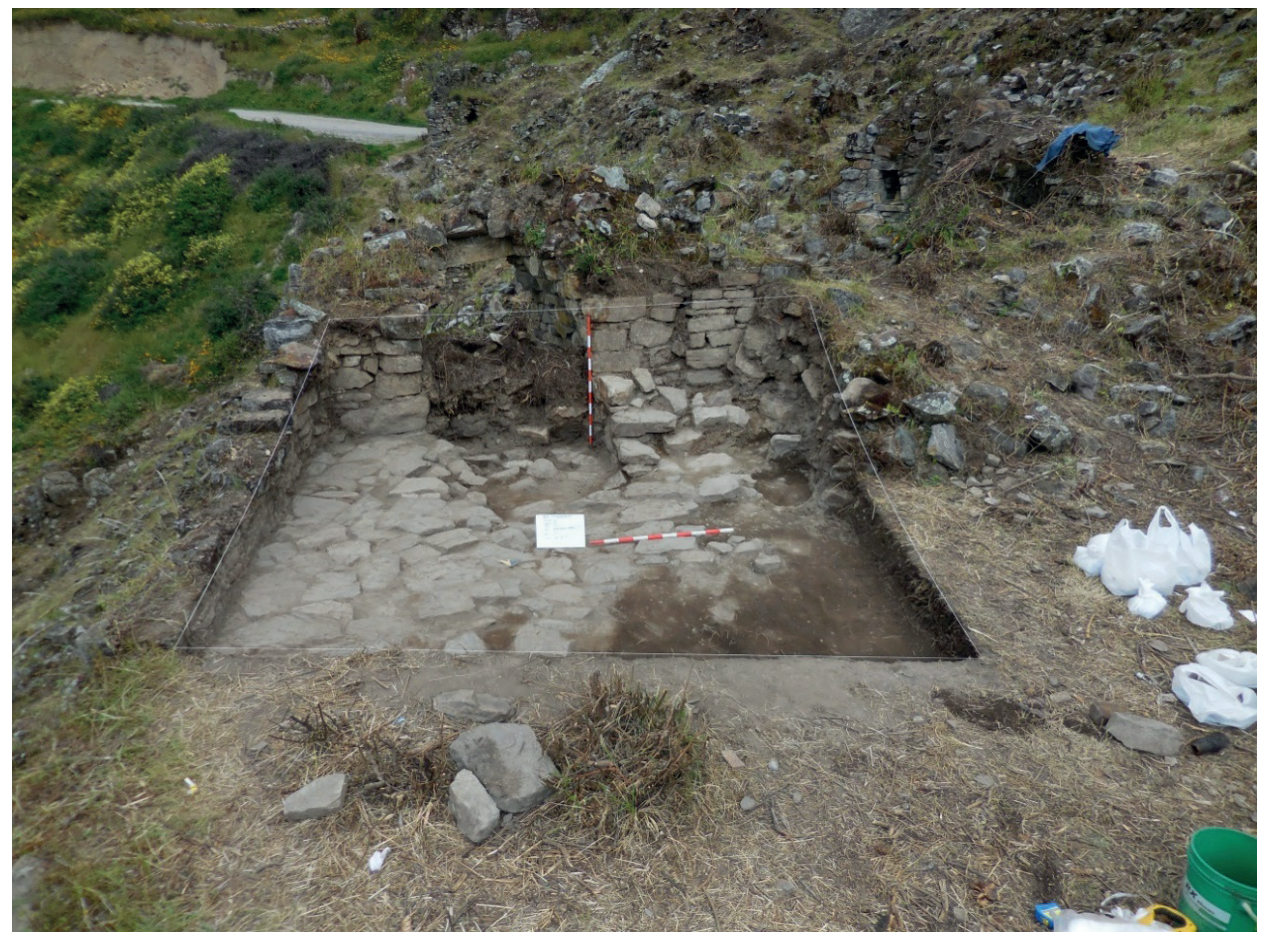

Figura 5: Vista final de la unidad de excavación 8 de Marca Piche (2015). Sobre el piso empedrado del patio se recuperó los restos de cuatro cuyes. humanos (dientes, huesos largos, costillas, falanges, lumbares, fémur) y algunos restos de óseos de cuy (mandíbulas). Después de la capa Superficial se identificó la capa E, compuesta por tierra suelta de granos finos, de consistencia semicompacta, de color gris oscuro, con inclusuiones de restos óseos humanos y regular presencia de restos óseos de cuy. También se halló fragmentos de cerámica (generalmente restos no diagnósticos), restos de textil, algunos restos botánicos como tuza y dientes de maíz, y unas semillas no identificadas, además de los restos de caña brava (posiblemente de algún tipo de cestilla que servía como asiento para el individuo. Todo esto formaba parte del contexto funerario.

En la unidad de excavación 6, lado oeste del sector $\mathrm{B}$, al frontis de un peñón, emplazada sobre un kullpi que ha derruido sus muros hacia la parte interior del mismo, se identificó seis contextos funerarios. El contexto funerario 4, está conformado por la deposición simple (sin estructura funeraria) de restos óseos humanos, al parecer disturbados por el derrumbe del Kullpi, correspondiente a varios individuos (por lo menos 10 individuos). Entre las asociaciones se halló fragmentería cerámica, proyectiles líticos, un percutor lítico, husos textiles, una figurina antropomorfa cerámica, tupus de cobre, un caracol, restos óseos chancados y mordidos de llama, restos óseos de cérvidos asados (pachamanca) y restos óseos de cuy (una escápula derecha adulta completa y una vértebra lumbar de individuo adulto). Asimismo, se recuperó otros restos de cuyes, conformados por: un cráneo adulto fracturado en los premaxilares y un húmero joven de lado izquierdo con la epífisis proximal no fusionado; evidenciando que este cuy ha sido comido asado durante los rituales funerarios. También se recuperó en esta capa, los restos de un cuy silvestre o curi (Cavia aparea tschudi), conformado por un fémur izquierdo completo de individuo adulto.

Por su parte, en la unidad de excavación 8 , emplazado en un espacio abierto, junto a un edificio kullpi, en el lado este del sector B, se identificó que se trataba de un patio con el piso empedrado con lajas de forma poliginal, desde el cual se ingresaba a un Kullpi a través de un vano. En la capa A (sobre el empedrado) se identificó restos óseos humanos quemados en asociación con restos óseos de camélidos (alpacas), ocho ukush o ratón silvestre (Phyllotis pictus) y por lo menos cuatro cuyes (tres cráneos, tres mandíbulas, cinco húmeros, nueve tibias, ocho fémures, tres radios y cuatro cúbitos).

La unidad de excavación 12 se encuentra emplazado en un patio situado en medio de un conjunto de edificios kullpi y chulpas. Durante el desarrollo de la excavación se identificó tres contextos funerarios en la 


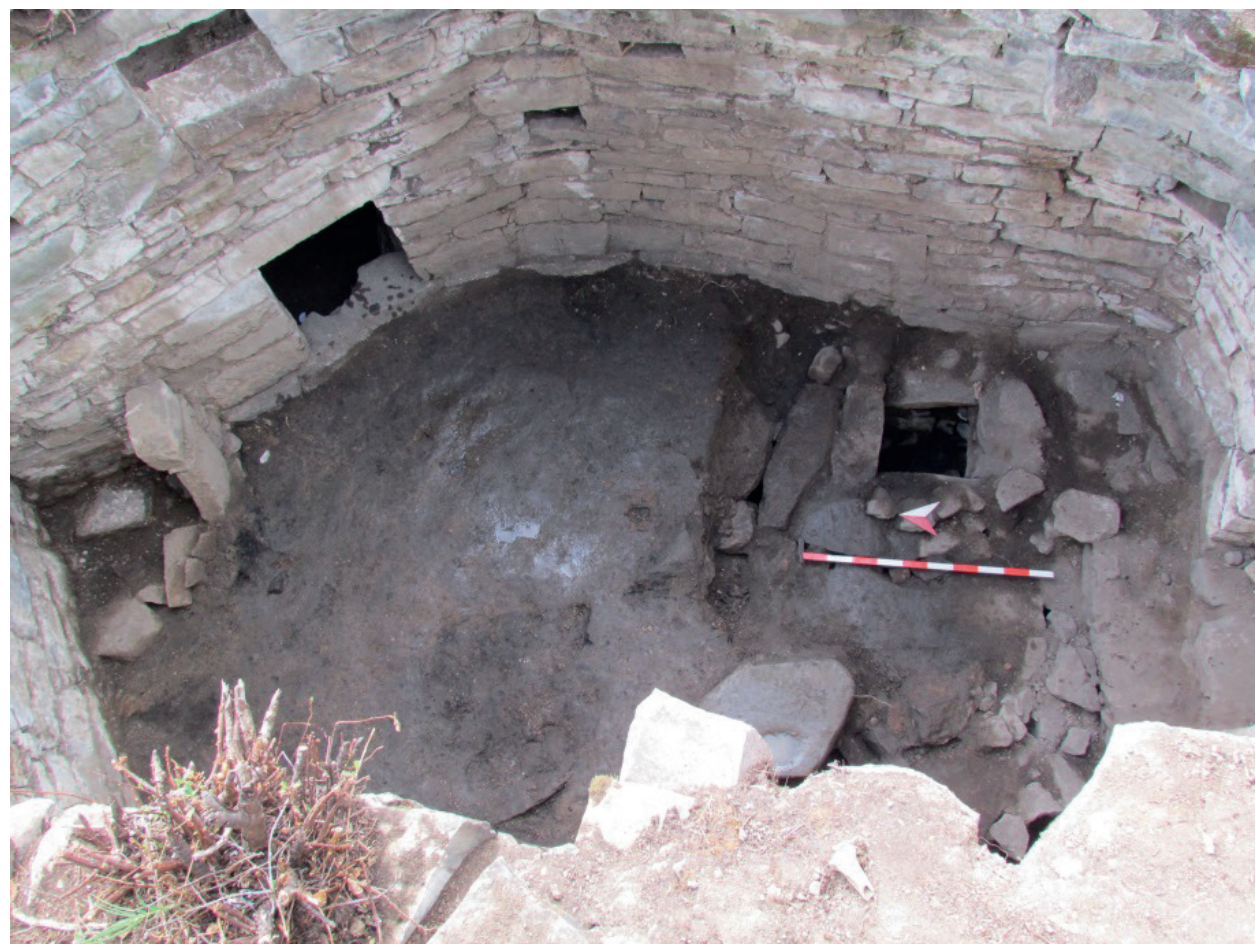

Figura 6: Vista panorámica de la cámara de subterránea (abierta). capa B. En esta misma capa se recuperó restos óseos y dientes de llamas, alpacas, un caracol terrestre, restos óseos de zorrino o añas (Conepatus rex), restos óseos de puma (Felis concolor), una mandíbula de guangana (Tayassu tajacu); restos óseos, dientes y astas de tarukas (Hippocamelus antisensis); así como una mandíbula izquierda de un cuy joven, la cual ha sido asada en pachamanca. Estos restos óseos formaban parte de ofrendas y banquetes desarrollados en este patio en honor a los ancestros que se encontraban al interior de las chulpas y kullpis contiguos; así como ofrendas al apu Chiwiria que se encuentra justo frente al patio y que se visualiza como imponente guardián y protector de la población que vivió en Marca Piche y del mismo asentamiento.

En la temporada de excavación 2017 se recuperó también en Marca Piche abundantes restos de cuyes. Sin embargo, la más importante corresponde al hallazgo ceremonial del interior de un Kullpi en la unidad 7 (van Dalen; 2018), donde debajo del hallazgo del desmonte producto del colapso de techo y cinco contextos funerarios (entre las asociaciones también se halló restos de cuyes), se halló al nivel del piso, una cámara subterránea con el vano cuadrangular, conteniendo al interior como relleno, tierra arcillosa y orgánica de color marrón, con inclusión de 10 fragmentos de cerámica, dos vasijas enteras, morteros pequeños (4), fósiles (19), puntas de proyectil (39), pulidores (71), boleadoras de huaraca (1) y conopas de batracios (4), cuyes (30) y camélidos (17). Las conopas o illas de cuyes están elaboradas en roca basalto, de coloración griss y superficie pulida.

Las evidencias de cuyes recuperadas del sitio arqueológico de Marca Piche, evidencian que estos animalitos eran muy importantes en las ofrendas funerarias, colocadas enteras o cocinadas mediante pachamanca en la tierra, ofrendada a los muertos y los ancestros. El hallazgo de cuyes en patios o espacios abiertos, indica que también era ofrendado a los apus tutelares y divinidades locales. Los cuyes también formaban parte de la dieta proteica de la población del pueblo de Marca Piche, pues sus restos corresponden al $21.40 \%$ de restos óseos hallados, consumidos en forma asada o kaspan, probablemente junto con los choclos, papas, camotes, maní, frijoles, zapallos y diversos frutales. Asimismo, había ceremonias religiosas donde se sacrifican cuyes.

Las investigaciones desarrolladas en el sitio de Araro, en la Comunidad Campesina de Santa Cruz de Andamarca, revelaron también el hallazgo de restos de cuyes, al interior de los edificios Kullpi. Por ejemplo, al interior de un Kullpi en la unidad 8, se halló como parte de los hallazgos colocados sobre el piso de la cámara principal, el hallazgo 6, conformado por el 

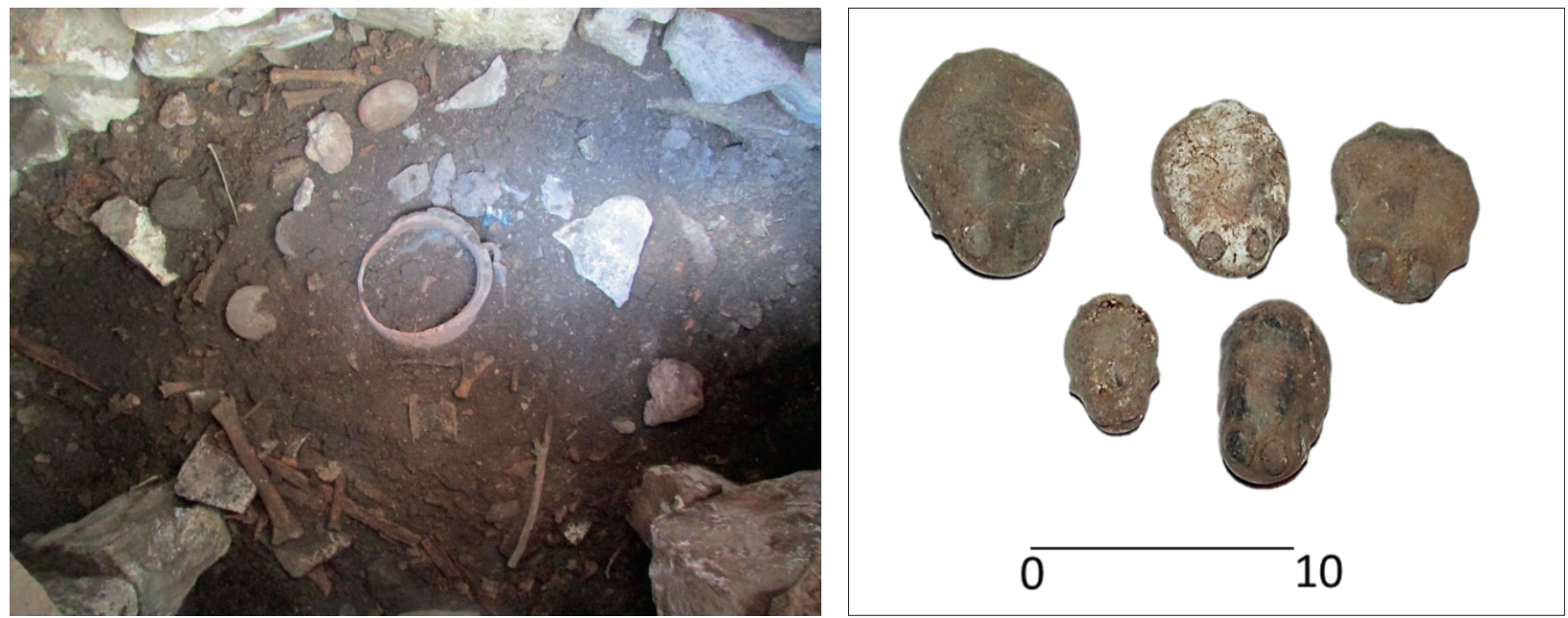

Figura 7 (izquierda): vista de las ofrendas de la cámara de subterránea, Marca Piche. Figura 8 (derecha): Vista de conopas de cuyes de la cámara subterránea.

cráneo de un cuy, parcialmente fragmentado, asociado a un vaso pequeño de madera y a un batán. De igual manera, en la unidad 13, al interior de un recinto rectangular, como parte de las ofrendas asociadas al contexto funerario 1, se halló los restos óseos de un cuy, asociado a: piruros de cerámica, morteros y pulidores.

\section{El uso del cuy en las comunidades de indígenas de la cuenca alta del río Chancay-Huaral durante la Colonia}

Desde el momento de la invasión hispana y a pesar de las violentas campañas de extirpación de idolatrías, destinadas a erradicar todo tipo de manifestación religiosa andina, el cuy se mantuvo vigente en cuanto a su importancia mágico religioso. Sin embargo, a diferencia de los periodos prehispánicos, en que su uso se realizaba de manera pública y en grandes espacios abiertos, a vista de toda la sociedad, en el periodo Colonial su uso se realizaría en un ambiente más privado, esto por temor a los castigos y represalias del clero cristiano. El antiguo territorio cultural de los Atavillos, en la Colonia perteneciente al corregimiento de Canta, fue organizado por curatos y pueblos, los cuales se formaron mediante las reducciones de pueblos. En la jurisdicción de cada pueblo de fundación colonial había uno o más de los llamados «pueblos viejos", que eran los pueblos prehispánicos de cada uno de los ayllus que en el primer siglo colonial fueron reducidos. A pesar de haber sido obligados a despoblar sus pueblos originarios, la población local y sus descendientes aún mantenían una relación de identidad y sentimiento para con estos lugares, donde ciertas épocas del año llegaban a realizar sus ofrendas y a rendir culto a sus antiguas divinidades, a sus apus y a sus ancestros. Similar situación se vivía en las áreas domésticas y rurales, fuera del alcance de la vista de los curas hispanos, realizando en sus actividades cotidianas el culto a las divinidades tutelares y el pago a la tierra. En estas actividades el cuy siguió cumpliendo un papel importante.

Se conoce poca información etnohistórica, visitas y documentos administrativos de estos pueblos de la cuenca alta del río Chancay; sin embargo existen algunos de extirpación de idolatrías que evidencian el uso del cuy en las ceremonias religiosas como elemento ritual. Un documento de extirpación de idolatrías de 1697 narra una serie de sucesos desarrollados en San Miguel de Vichaycocha (van Dalen; 2014b). En el documento, Don Martín de Sosa, curaca principal del pueblo de San Miguel de Vichaycocha, permanece detenido en la cárcel del pueblo de Concepción de Pásac acusado de brujo, por el mercedario fray Pedro Gudino (cura interino del repartimiento de Pacaraos), por poseer en el pueblo de San Miguel de Vichaycocha un ídolo en el lugar llamado Colquimaro. Al llegar a este lugar encontraron: «dos piedras en forma de sapos, dos cuyes degollados, dos callanas a manera de lámparas con cuio fresco y dos velas puestas en las dos piedras y un cuerpo de los antiguos seco y entero en postura de estar sentado» (Ibid: 252). Fue capturado un sospechoso de ser cómplice de Sosa, el Sr. Juan Chinchaypuma 
vecino del pueblo de Vichaycocha, que admitió que iban a una huaca donde servían chicha en un cántaro y se lo ofrecían a una momia (mallqui). Encendían una vela, ponían el ídolo en un plato y degollaban un cuy, cuya sangre caía en otro plato (una «bimetilla de vino y sangre»). A este acto lo llamaban «mochavan» $\mathrm{o}$ «mochadero». Este lugar se ubicó en el Ingenio de Santa Catalina, donde se encontró illas o conopas con figuras de sapos, vicuńas, maíz, papas, fragmentos de vasijas hecho candiles, cuyes podridos y huesos de humanos.

En los vecinos corregimientos de Cajatambo y Chancay, los documentos de extirpación de idolatrías refieren el uso recurrente del cuy como parte de las ofrendas que se realizaban en los siglos XVI y XVII a las huacas y mallquis, muy importante en las interrelaciones entre los hombres y sus divinidades (Duviols; 2003, Huertas; 1981, Sánchez; 1991).

\section{El cuy en las comunidades altoandinas actuales de la provincia de Huaral}

La provincia de Huaral tiene 36 comunidades Campesinas altoandinas, distribuidas en 9 distritos. En muchas de ellas, hasta la actualidad el cuy es un animal muy apreciado por la población local, como en todos los Andes sudamericanos.

\section{a. El jubeo con cuy}

Una de las funciones principales del cuy es como instrumento medicinal y de adivinación, mediante la «soba» o «jubeo», con el fin de diagnosticar y curar a las personas que padecen alguna enfermedad. En muchas comunidades donde actualmente no hay servicios médicos (postas de salud, centros de salud y hospitales), las personas que se enferman acuden a especialistas en curación con métodos tradicionales (Arellano; 2000). La soba del cuy es un procedimiento de diagnóstico, pronóstico y curación de enfermedades, el cual se realiza frotando con un cuy por todo el cuerpo del paciente o enfermo, sacrificando luego al animal para examinar su organismo (Reyna; 2002: 13).

San Miguel de Vichaycocha, era un pueblo considerado por los espańoles como «tierra de brujos», por las prácticas tradicionales de curación que realizaban muchos de sus pobladores, con una gran fama que eran conocidos y requeridos en otras comunidades de la cuenca alta del río Chancay - Huaral y en los actuales departamentos de Pasco, Junín y la provincia de Canta.

Entre las enfermedades que los especialistas señalan identificar mediante el jubeo figuran: el «mal aire», el «abuelo», el «mal del apu o cerro» y el «daño». $\mathrm{El}$ «mal aire» es tomado cuando la persona se desplaza en la madrugada y los fuertes fríos de la cordillera impactan en el cuerpo, generando dolores musculares y contracción de las partes del cuerpo. El «mal del abuelo» es adquirido al transitar por las zonas arqueológicas, cuevas u otros espacios que contienen restos de las poblaciones prehispánicas, en especial restos humanos; se presenta por no realizar el "pago» correspondiente (con coca, licor y cigarros), pidiendo permiso a los ancestros para transitar por estas áreas. $\mathrm{El}$ «mal del cerro o del apu» se adquiere cuando una persona está transitando por las alturas, cerca al área de los cerros tutelares conocidos como apus, sin hacerles el "pago al cerro». El «daño» o brujería es hecha por otras personas por alguna rińa o envidia, con la finalidad de matar a una persona de diferentes maneras en corto, mediano o largo plazo.

En la actualidad, los especialistas en la curación de enfermedades con cuy, tienen variadas formas y métodos de desarrollar este proceso. Sin embargo, el más común cuenta con la participación de otros ingredientes naturales (vegetales y minerales). Este proceso lo realizan generalmente los días martes o viernes, días considerados apropiados para el proceso de curación. Para ello, se debe conseguir un cuy de mediana edad y de color negro. Si el paciente es de sexo femenino se deberá sobar con un cuy hembra, pero si es de sexo masculino con un cuy macho. Un ingrediente importante que acompaña al cuy en el proceso de curación es la hoja de coca. Otro ingrediente importante es el «ashancoi», una planta herbácea pequeña que crece en la región puna en zonas rocosas, por lo general en acantilados o abrigos rocosos, muy difícil de hallar por su gran escasez. Las hojas de esta planta se hacen secar y se mezclan con granos de maíz negro, siendo todo molido conjuntamente.

\section{b. El cuy como ingrediente gastronómico}

A través de todos los tiempos culturales, el cuy ha sido preparado de diferentes maneras (Antúnez de Mayolo; 2001: 154-177), situación que se mantiene 
hasta hoy en las comunidades altoandinas de Huaral. En la actualidad las comidas elaboradas a base de cuy son frecuentes en casi todas las regiones del Perú (Ravines y Villiguer; 2016). En la gastronomía regional huaralina, tanto en sierra como en Costa, el cuy es un producto que se suele preparar en días festivos familiares, principalmente en días de cumpleaños, bautizos, matrimonios, entre otros. El potaje más común a base de cuy es el cuy frito, servido con papas y ajíes, pudiendo estar roceado con un aderezo de yerbas. También es frecuente el cuy preparado en pachamanca, acompañando a otras carnes como la res, el carnero o la alpaca; así como papa y verduras. El cuy guisado con ají o al estilo pepián, con choclo es también muy recurrente; así como en caldos como el "patachi», muy común en la región. Los caldos a base de cuy son consumidos por personas que padecen de alguna enfermedad, están en recuperación de alguna operación o para mujeres antes y después del embarazo.

\section{c. El cuy como instrumento ritual}

En la actualidad aún perviven las costumbres rituales ancestrales en muchas de las comunidades altoandinas de la provincia de Huaral. En días de faenas comunales en lugares alejados del pueblo se suele sacrificar cuyes como parte del "pago a la tierra» o del "pago o permiso a los apus». En este proceso ritual de sacrificio de cuyes a los dioses, el acompañante siempre es la hoja de coca. Participan todos los comuneros. Estos rituales en los que se solicita permiso a las divinidades para el inicio de las festividades, faenas y otras actividades sociales colectivas, simbolizan la relación entre los miembros de las comunidades y sus deidades protectoras, celosos guardianes protectores de todos sus hijos, pero a la vez drásticos castigadores de estos cuando se olvidan de rememorarlos en estos rituales.

\section{d. La crianza de cuyes en las comunidades altoandinas de Huaral}

En las últimas décadas, la crianza de cuyes en las comunidades altoandinas de Huaral ha disminuido considerablemente. La crianza se sigue desarrollando en el ámbito doméstico, principalmente en la vivienda ubicada en el pueblo. Las personas que crían cuyes tienen alrededor de una decena (en promedio), los cuales son criados en medianas cuyeras ubicados junto a la cocina o de forma libre en la cocina. En pocos casos se cría a los cuyes en las estancias donde se encuentran las chacras o las "vaquerías». La alimentación consiste de plantas arbustivas y herbáceas que crecen en el ámbito territorial de la comunidad. La crianza de estos cuyes se desarrolla para consumo familiar y en algunos casos para ser utilizados en el jubeo de los miembros de la familia. Muy pocas personas venden los cuyes que crían.

\section{Conclusiones}

A través del proceso histórico, desde la consolidación de la sociedad Atavillos hasta la actualidad, el cuy ha sido un animal muy importante para las sociedades que se desarrollaron en la cuenca alta del río Chancay-Huaral, actual provincia de Huaral. En épocas prehispánicas, la importancia del cuy giraba en torno a tres funciones principales: como ingrediente gastronómico, con el cual se elaboraban múltiples potajes en fechas festivas o cotidianas; como instrumento medicinal, utilizado para el diagnóstico y cura de enfermedades mediante la soba o jubeo; $y$ como ingrediente fundamental en ritos y ceremonias religiosas mediante el sacrificio a divinidades y ancestros.

Los restos óseos de cuyes que se han recuperado de las excavaciones en los sitios arqueológicos de la cultura Atavillos, corresponden a contextos de ofrenda y de restos de comida. El consumo de cuy en la dieta de la población local atavillana fue común y de alta frecuencia, por ello su hallazgo al interior de los Kullpis y en los patios y espacios abiertos contiguos. Pero también, se han recuperado en considerables cantidades al interior de contextos funerarios, formando parte de las ofrendas enteros, en algunos casos sacrificados en honor al difunto y en otras, preparados con otros alimentos para que sirvan de compañía al difunto en el paso al mundo de los muertos, o traídos cada ańo durante el culto a los ancestros y colocados al interior de los contextos funerarios. El hallazgo de numerosas conopas con representaciones de cuyes confirma su importancia en los contextos rituales. 


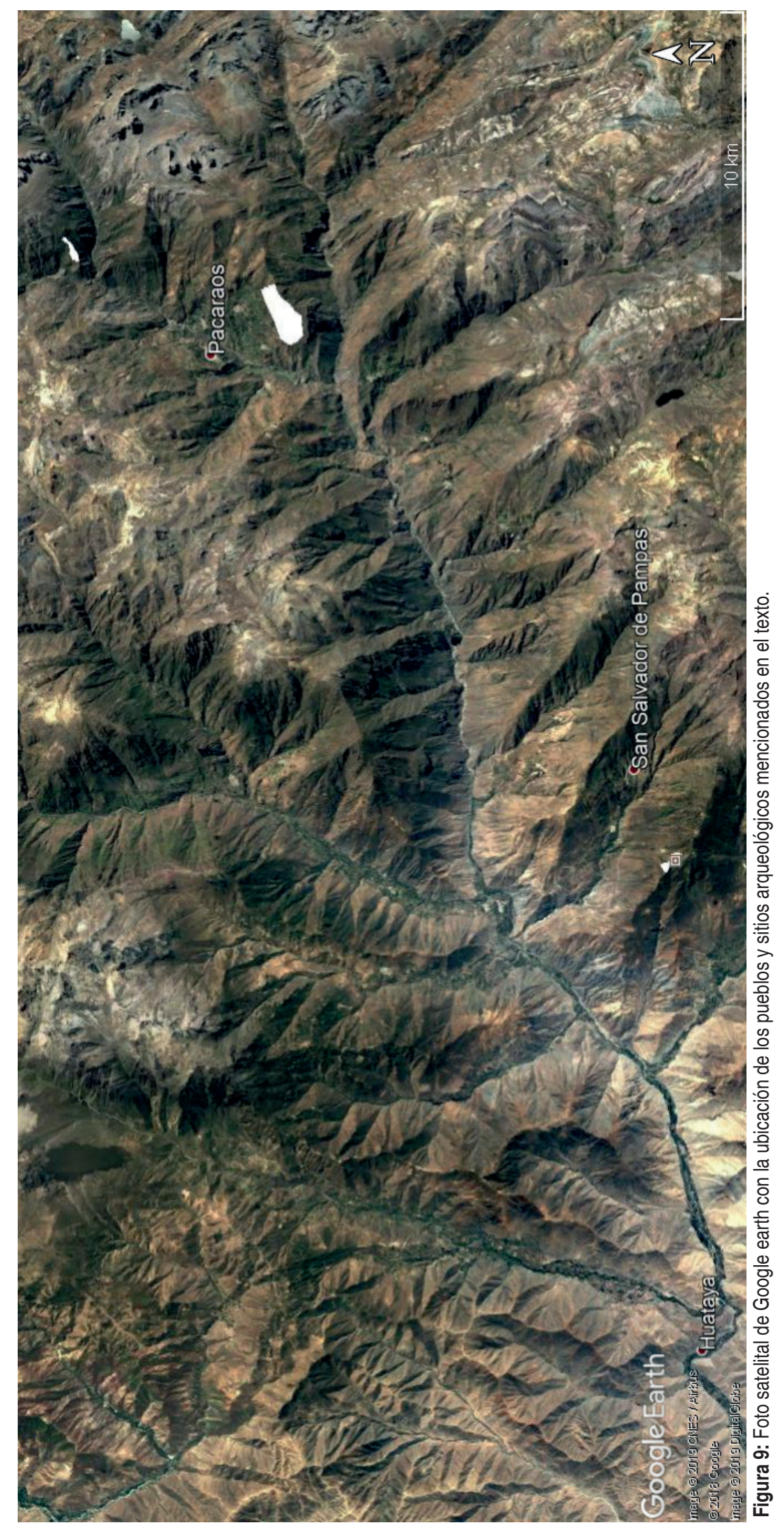


Tras la invasión hispana, a pesar de las violentas campañas de extirpación de idolatrías, las antiguas prácticas realizadas con el cuy se mantuvieron, aunque pasaron de un ámbito público al privado. La poca información etnohistórica hace referencia del uso del cuy en el culto a las divinidades andinas (huacas).

En la actualidad, a pesar de haber transcurrido casi 500 años desde que se inició el proceso de desestructuración andina, las comunidades campesinas altoandinas de la provincia de Huaral, mantienen vigentes muchas de sus prácticas culturales ancestrales (continuidad cultural), entre estas el uso del cuy con fines medicinales, alimenticios y rituales. En la actualidad la crianza del cuy se realiza dentro de un sistema doméstico para el autoconsumo.

\section{Bibliografía}

Acosta, Jose de (1590 [1954]). Historia natural y moral de las Indias. Biblioteca de Autores Españoles. Tomo 73. Madrid: Ediciones Atlas, 247 pp.

Altamirano Enciso, Alfredo (1986). "La importancia del cuy: un estudio preliminar». Serie Investigaciones. No 8. Escuela Académico profesional de Arqueología, Gabinete de Arqueología - Colegio Real. Lima, 63 pp. Anónimo (Jesuita) (1594 [1968]). «Relación de las costumbres antiguas de los naturales del Peru». Biblioteca de Autores Españoles. Tomo 209. Crónicas Peruanas de Interés Indígena. Ediciones Atlas. Madrid, pp. 151-189.

Antúnez de Mayolo, Santiago (1980). «La nutrición en el antiguo Perú». Actas y trabajos del III Congreso Peruano del Hombre y la Cultura Andina. Tomo V. Ramiro Matos, editor. Lima, pp. 811-828.

Antúnez de Mayolo, Santiago (2011). La nutrición en el antiguo Perú. Lima: Sociedad geográfica de Lima, 240 pp.

Arellano Guerrero, Jesús Angel (2000). "Crianza andina del cuy frente a los modelos de desarrollo». En: Manos sabias para criar la vida: Tecnología andina. Juan van Kessel y Horacio Larraín Barros, editores. Simposio del 49० Congreso Internacional de Americanistas. Quito: Ed. Abya-Yala, pp. 191-200.

Arriaga, Pablo Jose de (1621 [1968]). «Extirpación de la idolatria del Piru». Biblioteca de Autores Espańoles. Tomo 209. Crónicas Peruanas de Interés Indigena. Ediciones Atlas. Madrid, pp. 191-277.
Bolton, Ralph y Calvin, Linda (1981). «El cuy en la cultura peruana contemporánea». Runakunap Kawasayninkupaq. La tecnología en el mundo andino: subsistencia y mensuración. H. Lehtman y A. Soldi, editores. Universidad Nacional Autónoma de MéxicoUNAM, Instituto de investigaciones antropológicas. México D.F., pp. 261-326.

Bolton, Ralph; Calvin, Linda; Flores OchoA, Jorge A. (2012). Alpacas y cuyes en la etnografía andina. Serie: Antropología y etnología, 12. Universidad Nacional del Altiplano. Puno, 297 pp.

Cabello Valboa, Miguel (1951 [1586]). Miscelanea antartica: una historia del Peru Antiguo. Lima: Instituto de Etnología, Facultad de Letras, Universidad Nacional Mayor de San Marcos, 483 pp.

Cabrera, Angel (1953). "Los roedores argentinos de la familia Caviidae». Libro de publicaciones. No 6. Universidad de Buenos Aires. Buenos Aires, pp. 48-56.

Chauca, Lilian (1997). "Producción de Cuyes (Cavia porcellus)». Organización de las Naciones Unidas para la Agricultura y la Alimentación. (FAO). No 138, vol. 1-3. Lima, 53 pp.

Chirinos, Octavio; Muro Mesones, Krishna; Concha, Willy Álvaro; Otiniano, Javier; Quezada, José Carlos; y Ríos, Víctor (2008). Crianza y comercialización de cuy para el mercado limeño. Universidad ESAN. Lima, 192 pp.

Duviols, Pierre (2003). Procesos y visitas de Idolatrías. Cajatambo, siglo XVII. Lima: Pontificia Universidad católica del Perú, Instituto Francés de Estudios Andinos. 882 pp.

Espinoza Soriano, Waldemar (1997). Los Incas. Economia, sociedad y estado en la era del Tahuantinsuyo. Ed. Amaru. Lima, 507 pp.

Gade, Daniel (1967). "The guinea pig in the Andean Folk culture». The geografical review No 57 (2). USA, pp. 213-224.

Garcilaso de la Vega, Inca (1976 [1609]). Comentarios reales de los Incas. Tomo I. Biblioteca Ayacucho 5. Libro I-V. Caracas.

Guillén, Karina; Grandez, Ricardo; Chauca, Lilia; Chauca, Denise; y Valencia, Roberto (2015). «Estudio descriptivo de la anatomía radiográfica ósea del cuy (Cavia porcellus) no mejorado y el cuy mejorado raza Perú». Salud y Tecnología Veterinaria. Vol. 3, No 2. Universidad Peruana Cayetano Heredia. Lima, pp. 68-77 
Henan, Ibsen (1956). The guinea pig. Kansas State University. Kansas, 250 pp.

Matienzo, Juan de (1967 [1567]). Gobierno del Perú. Travaux de l' Institut Francais d'Etudes Andines. No 11. Lima, 366 pp.

Huertas Vallejos, Lorenzo (1981). La religión en una sociedad rural andina, siglo XVII. Universidad Nacional San Cristóbal de Huamanga. 158 pp.

Murúa, Martín de (1962 [1590]). Historia general del Perú. Origen y descendencia de los Incas. Tomo I. Colección Joyas Bibliográficas, Biblioteca Americana Vetus. Instituto Gonzalo Fernández de Oviedo. Madrid, $274 \mathrm{pp}$.

Murra, John V. (1972). «El control vertical de un máximo de pisos ecológicos en la economía de las sociedades andinas». Visita de la provincia de León de Huánuco en 1562 de Iñigo Ortiz de Zúñiga. Universidad Nacional Hermilio Valdizán. Huánuco, pp. 427-476.

Pulgar Vidal, Javier (1952). El curi, cuy, sucuy, cuye, jaca o conejillo de indias en Colombia (Cavia Cobaya). Ministerio de agricultura de Colombia. Ed. Minagricultura. Bogotá, 204 pp.

Ravines, Rogger y Villiger, Fernando (2016). «El cuy en la gastronomía peruana». En: Boletín de Lima No 183. Ed. Los Pinos. Lima, pp. 43-93.

Reyna Pinedo, Víctor (2002). La soba o limpia con cuy en la medicina tradicional peruana. Lima, $116 \mathrm{pp}$.

SÁnchez, Ana (1991). Amancebados, hechiceros y rebeldes (Chancay, siglo XVII). Centro de Estudios Regionales Andinos Bartolomé de las casas. Cusco, 255 pp.

Spotorno, Angel; Manríquez, Germán; Fernández, Andrea; Marín, Juan Carlos; Gonzales, Fermín y Wheeler, Jane (2007). «Domestication of Guinea Pigs from a Southern Peru - Northern Chile wild species and their middle pre-columbian mummies». The Quintessential Naturalist: Honoring the life and legacy of Oliver P. Pearson. D. A. Kelt, E. P. Lessa, J. Salazar-Bravo y J. L. Patton, editores. Zoology, No 134. University of California Publications. California, pp. 367-388.

van Dalen Luna, Pieter (2007). «Reconocimiento Arqueológico en la cuenca alta del río Chancay-Huaral: margen izquierda, (distritos de Atavillos Alto, Santa Cruz de Andamarca y Pacaraos). Nuevos datos para comprender los procesos socio culturales Atavillos». Revista Cultural Kullpi. Investigaciones culturales en la provincia de Huaral y el Norte Chico. №3. Huaral, pp. 57-148.

van Dalen Luna, Pieter (2010). «Investigaciones arqueológicas en Marca Piche: sitio Atavillos en Baños, cuenca alta del río Chancay - Huaral». Boletín de Lima No 159. Lima, pp. 22-34.

van Dalen Luna, Pieter (2014a). Apuntes para el estudio de la arqueología e historia de la comunidad campesina de San José de Baños, distrito de Atavillos Alto, provincia de Huaral. Ed. Juan Gutemberg. Lima, 212 pp.

van Dalen Luna, Pieter (2014b). «Un documento de extirpación de idolatrías de la Comunidad Campesina de San Miguel de Vichaycocha de 1697, Repartimiento de Pacaraos, actual provincia de Huaral». Kullpi. Investigaciones culturales en la provincia de Huaral y el Norte Chico. No 7. Lima, pp. 241-258.

van Dalen Luna, Pieter (2016). «Contextos funerarios Atavillos en Purunmarca, Vichaycocha, Huaral». En: Arqueología y Sociedad. No 30. Museo de Arqueología y Antropología, Universidad Nacional Mayor de San Marcos. Lima, pp. 39-100.

van Dalen Luna, Pieter (2018). Gestión de un patrimonio arqueológico olvidado por el Estado: propuestas para la recuperación cultural del sitio arqueológico de Marca Piche, San José de Baños, Huaral. Tesis para optar el grado académico de Magíster en Gestión del Patrimonio Cultural. Unidad de Post Grado, Facultad de Ciencias Sociales, Universidad Nacional Mayor de San Marcos. Lima, 398 pp.

van Dalen Luna, Pieter; Grados Rodríguez, Hans; Medina SÁnchez, Francisco y Malpartida Gamarra, Miller (2016). "Conviviendo con los ancestros: investigaciones arqueológicas en Rupac - Huaral». Arqueología y Sociedad No 30. Museo de Arqueología y Antropología, Universidad Nacional Mayor de San Marcos. Lima, pp. 425-472.

Villar Córdova, Pedro (1982 [1935]). Arqueología del departamento de Lima. Ed. Atusparia, $2^{\circ}$ edic. Lima, 423 pp.

WING, Elizabeth (1975). «La domesticación de los animales en los Andes». Allpanchis No 8. Cusco, pp. 25-44. 